\title{
Go Team! The Role of the Study Group in Academic Success
}

\section{Dr. Denise Wilson, University of Washington}

Denise Wilson is a professor of electrical engineering at the University of Washington, Seattle. Her research interests in engineering education focus on the role of self-efficacy, belonging, and other noncognitive aspects of the student experience on engagement, success, and persistence.

\section{Dr. Cheryl Allendoerfer, University of Washington}

Dr. Allendoerfer is a Research Scientist in the College of Engineering at the University of Washington.

\section{Prof. Rebecca A Bates, Minnesota State University, Mankato}

Rebecca A. Bates received the Ph.D. degree in electrical engineering from the University of Washington in 2004. She also received the M.T.S. degree from Harvard Divinity School in 1993. She is currently Professor and Chair of the Department of Integrated Engineering program at Minnesota State University, Mankato, home of the Iron Range and Twin Cities Engineering programs.

\section{Dr. Tamara Floyd Smith, Tuskegee University}

Dr. Tamara Floyd Smith is a Professor of Chemical Engineering at Tuskegee University.

\section{Dr. Melani I. Plett, Seattle Pacific University}

Prof. Melani Plett is a Professor in Electrical Engineering at Seattle Pacific University. She has over seventeen years of experience in teaching a variety of engineering undergraduate students (freshman through senior) and has participated in several engineering education research projects, with a focus how faculty can best facilitate student learning.

\section{Dr. Nanette M Veilleux, Simmons College}

Nanette Veilleux is a Professor and Director of the Computer Science and Informatics Program at Simmons College, Boston, MA. Her research interests include pedagogy in STEM disciplines, particularly with respect to women students and computational linguistics where she investigates the use of intonation in human speech.

\section{Ms. Mee Joo Kim, University of Washington- Seattle}

MJ Kim is a Ph.D. student in Educational Leadership, Policy \& Organizations Studies (Higher Education) at the University of Washington College of Education. She has been involved in a 5-institution, 5 -year, NSF-funded project that investigated to understand the impact of belonging and other connections to community on academic engagement for undergraduates in science, math, and engineering (STEM). Broad range of activities related to the research questions at hand included data collection (surveys, interviews, focus groups, and classroom observations), analysis of the data(quantitative, qualitative, and mixed), assessment and revision of research design, data presentation, and supervising undergraduates who are involved in the research team. Her current research interest is in assessing institutional strategies to embrace global consciousness among undergraduate students majoring in STEM disciplines. 


\title{
Go Team! The Role of the Study Group in Academic Success
}

\begin{abstract}
In this paper, we look at the communities and groups where engineering students work and learn outside the classroom, ranging from study groups to design project teams to professional society communities. Among four diverse institutions, we evaluate which academic communities, groups, or teams students participate in and when asked, which they tend to speak about more than others. We also probe more deeply into how and why the most effective teams or groups work for students. In a mixed methods approach, our quantitative (survey) data first show which academic communities students participate in and how active they are in these communities. Our qualitative data (interviews and focus groups) then explain how the most influential communities work for students. Our results show that while students reported participating at various levels, ranging from minimally to very active, in a broad range of academic groups available through their home departments and colleges, most (53\%) are active or very active in laboratory groups and a large number (42\%) are active or very active in informal study groups. In follow up interviews and focus groups, students also chose to discuss their experiences in study groups $(83 \%)$ or lab groups $(82 \%)$ but also commented frequently on their participation in professional societies. Of these students, most ( $87 \%)$ found benefit in participating in these groups, and a majority of the students $(72 \%)$ felt that they benefitted in ways related to operating within the group as an integral part of the team. Most students stressed the social learning provided by the group as compared to a single individual working alone.
\end{abstract}

\section{Introduction}

ABET (Accreditation Board for Engineering and Technology) requires that every undergraduate engineering student is active in teams (either formed by faculty or self-assembled) at some point in the undergraduate career. However, the full benefits of teamwork are not always realized in formal project teams. In fact, it is not uncommon for engineering students to complete work individually and then force fit the pieces together the night before a deadline. Some formal project teams do work extremely well, providing educational benefits that are unlikely to be realized by students working alone. However, those teams that students develop outside the classroom, with or without the help of a faculty member, can be just as important for supporting learning, engagement, and other academic outcomes as more formal project teams organized by faculty or instructors for specific purposes in individual courses.

\section{Background}

Academic project teams are only a small part of the full range of activities available to students. College students participate in a wide range of extracurricular or co-curricular activities, both within the home discipline or major and outside of it. Participation in extracurricular or cocurricular activities outside of engineering can enable engineering students to meet needs associated with belonging, safety (most often expressed as decreased anxiety), and self-esteem. ${ }^{1}$ Studies have also shown that participation in such activities improves scores on standardized measures of critical thinking skills. ${ }^{2}$ Other studies have focused on specific types of activities such as the role of intercollegiate athletics on improved persistence and graduation rates, ${ }^{3}$ higher 
levels of academic conscientiousness achieved through physical exercise and volunteering, ${ }^{4}$ and the significant positive impact of co-curricular activities outside the discipline on critical thinking skills. ${ }^{2}$

Most studies that look specifically at the benefits of student participation in academic cocurricular activities in higher education have focused on investigating learning communities. While the structure, frequency, and individual characteristics of learning communities vary from institution to institution, the term "learning community" broadly encompasses those communities that share a common purpose or vision, often in two or more courses, and are specifically designed to increase coherence among students and create a sense of community among them. ${ }^{5} \mathrm{~A}$ broad view of these communities and their impacts is warranted since, as Barbatis ${ }^{6}$ and Astin $^{7}$ caution, "it is a serious mistake to limit learning outcomes to only cognitive values". 6 For example, in their landmark review of how college affects students, Pascarella and Terenzini ${ }^{3}$ point to the importance of learning communities in promoting persistence as well as academic and social interaction. ${ }^{3}$ In a study of over 80,000 students at 365 four year institutions, Zhao and $\mathrm{Kuh}^{8}$ found that participation in a learning community was associated with engagement in active learning, increased interactions with faculty, and greater satisfaction with college. For some students, especially underrepresented students, a structured program that helps merge students' academic and social lives ${ }^{9}$ or supports social integration of academic concepts as well as a highlevel of faculty-student interaction and mentoring outside of content courses can be important for student success and retention. ${ }^{6}$

Long term membership in any study group, whether part of a formal learning community or not, has been shown to be positively related to achievement in medical programs. ${ }^{10}$ Similarly, Sokolove and Marbach-Ad ${ }^{11}$ found that out-of-class group activity significantly improved performance on exams. Formalized study groups, both online ${ }^{12}$ and face-to-face, ${ }^{13}$ associated with courses or programs in graduate-level social work have been shown to increase student satisfaction with the course and increased learning of course content. While the research on learning communities and other academic groups has predominantly pointed to beneficial outcomes from those groups, we know much less about which groups students participate in and what types of immediate benefits they perceive from these groups. While the ultimate outcome may be better grades, greater learning, or increased likelihood of persistence, what is it about working with peers on academic work that benefits students most?

This Study: This paper looks only at cocurricular activities that are directly related to the student's discipline and that occur outside the classroom with minimal supervision or facilitation by a faculty member or other instructor. This group of academic communities includes informal study groups, professional societies, laboratory and design project team activity, service learning, study abroad, and other learning-related activities that meet primarily outside the traditional, formal classroom experience. From these academic cocurricular teams, projects, and communities, we look more deeply into what students talk about most. Our research questions focus on the academic communities that students highlight the most both in surveys and interview/focus groups and the corresponding benefits experienced in those communities. Understanding how these activities influence students can help practitioners to measure the impact of these communities and to structure communities so that they benefit more students. 


\section{Methods}

This research is part of a larger five year, multiple institution research study that examines connection, community, and engagement in STEM education. In this larger study ${ }^{14}$, patterns of belonging, connection to community, and related affective outcomes are investigated with the goal of predicting and improving engagement and connection to community across a diverse range of institutions, students, teaching styles, and faculty. We are currently in the last year of this broader study funded by the National Science Foundation.

This part of the study focuses on engineers and on academic communities (those groups, projects, and teams chosen by students in relationship to their academic discipline or major). Data from four institutions of the five in our larger study were used for this analysis:

- HBCU (Bac-Div): A historically black, independent, and state-related institution of 2,605 undergraduates in the Southeast which offers four undergraduate engineering degrees and is typically characterized by small groups of students (class sizes of 5-50). Students can begin the engineering curriculum as early as first semester freshman year.

- Private/Faith Based (Masters L): A small teaching institution in the Pacific Northwest of 3,238 undergraduates, whose mission emphasizes building graduates of competence and character by providing tools of rigorous learning and modeling a grace-filled community. This institution offers six engineering and computer science majors that are based on and informed by a Christian world view. Class sizes typically range from 15-20.

- Research (RU/VH): A large research institution and flagship university in the Pacific Northwest which serves over 29,000 undergraduates and confers over 12,000 degrees annually. This institution offers ten engineering and computer science undergraduate degrees, and is characterized by large classes in freshman and sophomore years (100-500) and smaller classes in junior (40-80 students) and senior (15-40 students) year. Most students are competitively admitted to engineering and computer science majors after their second year.

- Teaching (Masters L): A medium-sized institution of approximately 13,504 undergraduates in the Midwest that combines an emphasis on teaching with emerging innovations in research, serving a regional student population. This institution offers over ten undergraduate degrees in engineering and computer science. Class sizes typically average 25 students, with upper division classes averaging about 15 students.

The fifth institution in this study is a small Women's College that offers a variety of STEM majors including computer science, but no engineering degrees. Since this study focused on engineering students (and computer science taught in the context of engineering), data from the Women's College were not included in this study.

A multi-phased mixed-methods approach ${ }^{15,16,17,18}$ was used to investigate how often and in what ways engineering and computer science students at four diverse institutions spend time in academic community outside the classroom (Figure 1). First, an exploratory sequential study (instrument development model) was completed in which focus groups with senior engineering and computer science undergraduates were asked to identify the academic communities in which 
they had participated over the course of their undergraduate careers. Data from this phase of focus group analysis was used to design the survey questions used in the explanatory phase of the study. The survey was provided to a much larger and broader population of engineering and computer science undergraduates in order to identify the frequency and level of participation in the academic communities identified by seniors in the first phase of the study. Finally, students were recruited from the survey population for interviews using questions designed to gain deeper insight into how and why student participation in academic communities influenced their academic experience at each institution. Results from the frequency analysis of survey data and qualitative insights citing benefits from participation in academic groups are the main focus of this study.

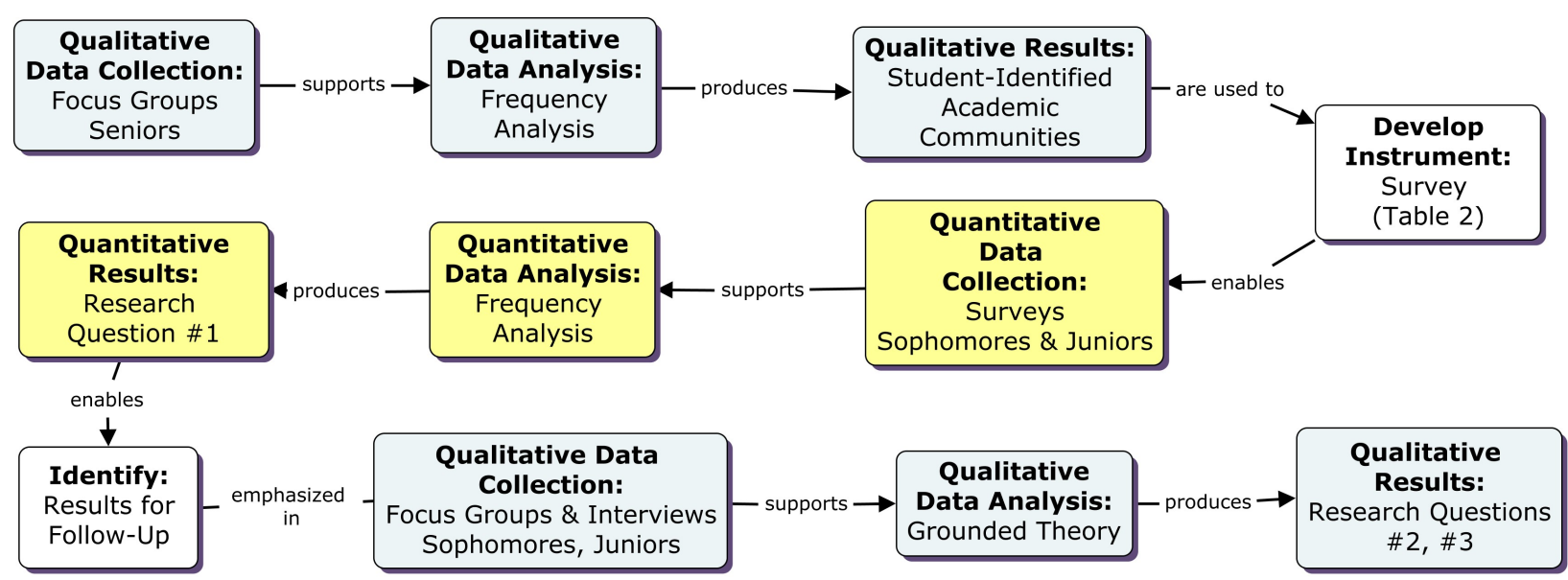

Figure 1: Research Design

The first row of the multi-phase research design diagram (Figure 1) shows the exploratory phase of this study while the last two rows show the explanatory phase. The exploratory phase contributes to the development of the survey instrument, while the explanatory phase uses the survey data as a starting point for developing qualitative data collection and analysis.

\section{A. Research Questions}

Three research questions were addressed in this part of our study.

\section{Research Question \#1:}

What does participation in academic communities look like among undergraduate engineering and computer science students?

This research question is quantitative and examines the prevalence of student participation in academic communities, as well as the degree to which students participated in them. This research question is important because it allows us to compare what students express in surveys vs. what they choose to discuss in focus groups and interviews and allows some insight into the differences between where students spend their time compared to which experiences have the most impact on their academic experience. 


\section{Research Question \#2:}

Which academic communities appear to have the most impact on engineering and computer science students?

This research question identifies what types of participation students tend to talk about most in focus groups and interviews and therefore, which academic communities are likely to have the most impact on these students, independent of how much time they spend in these activities.

\section{Research Question \#3:}

How does participation in academic communities benefit students the most?

This research question looks at what students see as the dominant benefit of participation in academic communities. This result has implications to practitioners and administrators who facilitate the formation of communities and teams as well as creating spaces for those communities to operate. Knowing what students gain from academic communities or groups outside of the classroom provides valuable insight into how to facilitate team membership as well as how to support the activities of teams.

\section{B. Subjects and Procedures}

Two groups of engineering and computer science students were involved in this study. The first group consisted of current or recent seniors at each institution and were recruited for the exploratory focus groups shown in the first row of the research design shown in Figure 1. The second group of students consisted primarily of sophomores and juniors and were recruited for a survey and a follow-up (explanatory) focus group (see Figure 1). No overlap occurred between the participants in the exploratory focus groups and subsequent participants in the surveys and explanatory focus groups. Total enrollments in engineering and computer science for each institution were approximately 900 (Research), 200 (HBCU), 460 (Teaching), and 100 (Private). In all phases of the study, a majority of student participants majored in electrical engineering, computer science, chemical engineering, and civil engineering, although a small number of students represented automotive engineering technology, mechanical engineering, industrial engineering, and materials science and engineering. Ethnicity data were collected for survey participants only and the ethnic make-up of the sample was 52.6\% White, $22.9 \%$ Asian, and $13.9 \%$ Black. Women and under-represented minorities were oversampled wherever possible. Participants from all four institutions were combined into a single sample population for this analysis. Additional detail including sample sizes, recruitment rates, gender, and institutional breakdowns for each phase of the study are shown in Table 1.

Exploratory Focus Groups (Spring 2010): During the Spring 2010 term, focus group participants were randomly recruited from the pool of engineering (including computer science) seniors at each institution. Participation in the study was voluntary, and students were assured that their responses would be confidential. Focus groups were recorded and transcribed, and all identifying information removed. Since the purpose of this phase of the study was to "cast the net" or explore the types of academic communities students discussed, self-select bias in the representativeness of students in the sample was not considered critically relevant or concerning.

Surveys (Fall 2010-Spring 2011): A sample of convenience including over 1000 engineering and computer science students began participation in this study by completing a survey of their experiences, including participation in communities both inside and outside of school, their feelings about the degree to which they belong (or do not belong) in these communities, and a 
variety of other demographics and affective indicators. Survey participants were recruited by researchers on each campus during the Fall 2010 and Spring 2011 terms. Like the focus groups, participation in the survey was voluntary, and students were assured that their survey responses would be confidential. Most subjects were recruited from core classes in each discipline required for the degree at sophomore and junior levels. Duplicate surveys were removed. Additional students were recruited as needed (to achieve a larger sample size) by e-mail using an electronic version of the survey and using similar recruitment protocols as with on-paper surveys.

Explanatory Focus Groups (Fall 2010-Spring 2011): After completing the survey, respondents were recruited to participate in follow-up focus groups. Explanatory focus group participants were recruited during the Fall 2010 and Spring 2011 terms. Recruiting for explanatory focus groups targeted primarily sophomores and juniors. Recruitment methods and other focus group procedures were similar to the exploratory focus groups described previously, except that the pool of subjects was drawn from students who had completed the survey. Because the students who agreed to participate in explanatory focus groups were self-selected, it is possible that some bias existed in the participant population. For example, students who chose to attend focus groups may have been those who were inherently more interested in community connections. The number of focus groups that were conducted represents the point at which data saturation was reached at each of the institutions or at smaller institutions, the point at which additional participants could not be recruited successfully.

Table 1: Participant Data

\begin{tabular}{l|c|c|c|c|c} 
Study Phase & Methods & Institution & Total $N(\%)$ & Men & Women \\
\hline \multirow{2}{*}{ Exploratory } & Qualitative: & HBCU & $7(19.4 \%)$ & $43 \%$ & $57 \%$ \\
& Focus Groups & Private & $9(25 \%)$ & $78 \%$ & $22 \%$ \\
& & Teaching & $8(22.2 \%)$ & $63 \%$ & $37 \%$ \\
& & Research & $12(33.3 \%)$ & $58 \%$ & $42 \%$ \\
\hline \multirow{2}{*}{ Exploratory/ } & Quantitative: & HBCU & $125(11.5 \%)$ & $59 \%$ & $41 \%$ \\
Explanatory & Surveys & Private & $71(6.5 \%)$ & $73 \%$ & $27 \%$ \\
& & Teaching & $254(23.4 \%)$ & $67 \%$ & $33 \%$ \\
& & Research & $636(58.5 \%)$ & $73 \%$ & $27 \%$ \\
\hline \multirow{2}{*}{ Explanatory } & Qualitative: & HBCU & $48(28 \%)$ & $64 \%$ & $36 \%$ \\
& Focus Groups & Private & $15(9 \%)$ & $78 \%$ & $22 \%$ \\
& Interviews & Teaching & $39(22 \%)$ & $71 \%$ & $29 \%$
\end{tabular}

\section{Instruments}

Exploratory Focus Groups: The purpose of the exploratory focus groups as relevant to this study was to identify academic and learning communities that engineering (including computer science) students identified as important to their academic experience. This phase of the research 
supported the design of survey questions used to investigate Research Question \#1 with regard to the types and levels of participation students commit to specific communities. To this end, the following questions from the exploratory focus group protocol were analyzed to identify important academic and learning communities:

- Which communities do you spend the most time in? (such as class, lab, study group, church, softball team, international student group, student trade society)

- Which communities are you most engaged in? In other words, which ones do you participate the most in?

- Which communities do you enjoy the most?

- Which communities at the $<$ name of institution $>$ make $<$ name of institution $>$ a special place for you where you feel that you can truly belong?

Each focus group lasted approximately one hour. Groups varied in size, ranging from 2 to 6 participants, with most groups including 2 to 4 students. Focus groups were facilitated by one to two researchers, who followed a semi-structured protocol that included the above questions.

Table 2: Questions Regarding Student Participation in Academic Community

\begin{tabular}{l|l}
\multicolumn{1}{c|}{ Question } & Response Scale \\
\hline $\begin{array}{l}\text { Select one response for each item to describe your level of } \\
\text { participation in the following types of activities or communities: }\end{array}$ & \\
Activities sponsored by your college & \\
Activities sponsored by your department/major & (1) No Participation \\
Design competition teams or design project groups & (2) Minimally Active \\
Faculty Led Groups & (3) Somewhat Active \\
(in class, office hours, other out-of-class events) & (4) Active \\
Informal Study Groups & (5) Very Active \\
Laboratory Groups & \\
An engineering/computer science/physics/mathematics society \\
(e.g., ASME, IEEE) \\
$\begin{array}{l}\text { Study Abroad Programs (including Engineers without Borders) } \\
\text { A professional or student group for women or minorities } \\
\text { (e.g., SWE, NSBE) }\end{array}$
\end{tabular}

Surveys: Quantitative survey data were used to answer the first of the three research questions in this study. In the survey, Likert scale questions asked students to rate their frequency of participation in a variety of academic communities (Table 2). The choice of activities included in this survey was based on the results of the exploratory focus groups just described. Although the short descriptions of each of these activities are open to individual student interpretation, the findings regarding students' reported levels of activity in specific areas were instrumental in 
guiding the focus group questions and prompts in order to understand how these activities influence the academic experience, as described next.

Explanatory Focus Groups and Interviews: Explanatory focus groups were similar to the exploratory focus groups, each including 1 to 8 participants and a semi-structured protocol based on the research questions and preliminary survey findings. In addition to the core questions, the protocol also included follow-up questions and prompts in order to obtain richer data when appropriate. These data were used to explore the last two research questions in this study. Analysis of the survey data guided development of the focus group protocol, as well as the analysis of the focus group data. The overall purpose of the explanatory focus groups was to gain additional insight into participation in academic communities beyond the basic level of participation students reported in the surveys. The results and analysis presented here emphasize the dominant benefit gained from participating in academic communities and activities, drawing primarily on data from the following question (and related probes):

- Of all the academic communities you participate in (for example, lab groups, informal study groups, the classroom, activities sponsored by the department, etc.), which help you the most to engage in your education? How do they help you?

\section{Results and Discussion}

In order to address the three research questions, both quantitative and qualitative methods were used in this multi-phased mixed methods study involving both exploratory-sequential and explanatory-sequential components.

Exploratory Focus Groups: Audio recordings or field notes were collected for each focus group. Transcripts and field notes from focus groups underwent frequency analysis to identify references to academic and learning communities. Those academic communities mentioned by at least two students were then integrated into the survey questions (Table 2).

Surveys: To support this study, frequency data were reported for the level of participation in specific academic communities as described in Table 2. Likert scale responses were divided into three categories for frequency analysis: Not Active (corresponding to a response of 1), Minimally or Somewhat Active (corresponding to a response of 2 or 3 ) and Active or Very Active (corresponding to a response of 4-5). No analyses of statistical significance were conducted of the survey data for this part of the study, as the purpose of the survey data was simply to guide the analysis of the subsequent explanatory focus group and interview data.

Explanatory Focus Groups: Nearly all focus groups were audio recorded and transcribed. In the few instances where focus group participants did not consent to audio recording, the researcher took extensive field notes, closely paraphrasing the exact words of the participants to the fullest extent possible to minimize bias. For these focus groups, excerpts from the researcher's notes are presented rather than exact quotes from participants.

\section{Research Question \#1:}

What does participation in academic communities look like among undergraduate engineering and computer science students? 
To address this question, quantitative survey data were analyzed first. The survey findings showed that students were most frequently "active or very active" in laboratory groups and informal study groups and least frequently active in study abroad programs, activities sponsored by the home college, and women/minority organizations (Table 3). More frequent and active participation in lab groups and informal study groups reflects overall the emphasis and priority that engineering students place on their studies, ${ }^{19}$ while on the other end of the spectrum, the infrequent participation in study abroad programs is consistent with generally low participation in such programs by engineers nationally, ${ }^{20}$ and may also be a result of the relatively rigid curriculum and time intensive nature of many engineering curricula. Infrequent participation in women's and minority organizations, such as SWE or NSBE, is likely a direct reflection of the small number of women in engineering ${ }^{21}$ as well as the low number of black students in the overall study population. For example, women made up $30 \%$ of the total survey population and $9 \%$ of survey participants reported they were active or very active in women and minority organizations. When the data for women/minority organizations are normalized by targeted populations, participation rates appear to be on par with activities in the home department, design projects/competitions, faculty led groups, and professional societies, but informal study groups and laboratory groups retain their position as the top two informal academic communities in which students are most often active.

Table 3: Frequency of Participation in Academic Communities

\begin{tabular}{l|c|c|c}
\multirow{2}{*}{\multicolumn{2}{c}{ Academic Community }} & \multicolumn{3}{c}{$\%$ of Students Reporting $(N=1086)$} \\
\cline { 2 - 4 } & $\begin{array}{c}\text { No } \\
\text { Participation }\end{array}$ & $\begin{array}{c}\text { Minimally or } \\
\text { Somewhat Active }\end{array}$ & $\begin{array}{c}\text { Active or Very } \\
\text { Active }\end{array}$ \\
\hline Activities in Home College & $25.9 \%$ & $70.3 \%$ & $3.8 \%$ \\
\hline Activities in Home Department & $30.7 \%$ & $45.3 \%$ & $24.0 \%$ \\
\hline Design Projects/Competitions* & $50.9 \%$ & $25.0 \%$ & $24.1 \%$ \\
\hline Faculty Led Groups & $29.0 \%$ & $44.7 \%$ & $26.3 \%$ \\
\hline Informal Study Groups & $17.0 \%$ & $40.9 \%$ & $42.1 \%$ \\
\hline Laboratory Groups & $17.7 \%$ & $29.2 \%$ & $53.1 \%$ \\
\hline Professional Societies & $42.8 \%$ & $35.6 \%$ & $21.6 \%$ \\
\hline Study Abroad Programs & $81.0 \%$ & $12.4 \%$ & $6.6 \%$ \\
\hline Women/Minority Organizations & $74.0 \%$ & $17.0 \%$ & $9.0 \%$ \\
*Including cocurricular projects and competitions open to students at all levels.
\end{tabular}

\section{Research Question \#2:}

Which academic communities appear to have the most impact on engineering and computer science students?

The qualitative data from the explanatory focus groups were then analyzed in order to gain deeper insight into students' participation in these academic communities. Looking at which communities interview participants cited as helpful, the qualitative data generally supported the quantitative findings, showing that overall, laboratory groups and informal study groups were the 
types of academic communities most frequently cited as helpful by participants (see Table 4). Although participants indicated activity in several additional types of academic communities on the surveys (as seen in Table 3), when asked in the focus groups about how participation in academic communities was helpful, participants did not elaborate on each community equally. Rather, the examples they chose to illustrate their experiences focused heavily on informal study groups, followed by lab groups or professional societies (depending on the institution), with virtually no mention of activities in the home department, design project competitions, or faculty-led groups.

Table 4: Most Helpful Academic Communities cited in Focus Groups \& Interviews

\begin{tabular}{l|l}
\multicolumn{1}{c|}{ Institution } & \multicolumn{1}{|c}{ Academic Communities (ranked by frequency of citation) } \\
\hline Private & $\begin{array}{l}\text { Informal study groups } \\
\text { Lab groups }\end{array}$ \\
\hline HBCU & $\begin{array}{l}\text { Informal study groups } \\
\text { Professional societies } \\
\text { Lab groups }\end{array}$ \\
\hline Research & $\begin{array}{l}\text { Informal study groups } \\
\text { Lab groups } \\
\text { Sessions with teaching assistants (TAs) } \\
\text { Study center }\end{array}$ \\
\hline Teaching & $\begin{array}{l}\text { Informal study groups } \\
\text { Professional societies }\end{array}$
\end{tabular}

These findings indicate that engineering students are active in a wide range of academic communities, and they report a subset of these communities as being especially helpful for their academic endeavors. It is important to note that although students' focus group discussions of helpful communities tended to center around a limited number of types of communities (primarily informal study groups, lab groups, and professional societies), this does not mean that participation in other types of academic communities is not important. As seen in the survey findings, students are indeed active in several other types of academic communities; however, the focus group findings suggest that students can more clearly see and articulate the connections between group participation and academic outcomes in the case of informal study groups, lab groups, or professional societies. These connections will be examined more closely in the following sections.

\section{Research Question \#3:}

How does participation in academic communities benefit students the most?

The qualitative analysis then turned to understanding how students participate in academic and learning communities. Most focus group participants (87\%) stated that they participated in academic or learning communities in some manner at least some of the time, and felt that doing so helped them academically. For those students who do participate in academic communities, most $(72 \%)$ reported that the primary benefit of participation was the social learning advantage to being in a group as compared to working alone. For example, several students commented on the positive impacts of teamwork in certain academic communities, including greater motivation, achievement, use of resources, and staying power when compared to the efficacy of the individual. For instance: 
"Being in my study group helps because with the combined brain power we're more likely to figure out the problems, get the correct answers, get better test scores and better grades." (Research)

"I'm involved in SWE [Society of Women Engineers]. I think that helps me a lot, for example when I went to the conference I felt motivated." (Teaching)

"Study groups [help] because we all get to bounce off ideas. If somebody figures [out] a different way of doing it, it kind of gives you a way to challenge what you think and helps." $(H B C U)$

"I've noticed definitely when I have a study group and then I don't, I definitely don't do as well in classes. Because even studying for a midterm together there's stuff sometimes I don't even realize I don't know until I've studied with somebody. And I'll bring up something to them, they'll bring up something to me. And it's like, wow, if I hadn't studied with you...then it would have definitely not resulted as well." (Research)

"Studying for a test, like, with 3 or 4 guys, we all try the same problem and when you finish you see how everybody approaches it and you see different ways to approach it and you learn off of that." (Teaching)

Among the students who discussed the positive power of the team in academic communities, a small number (approximately 3\% of the total focus group population) also recognized the competition provided by these communities, which they felt was a source of motivation to achieve. For example:

"I think there is an unspoken grades competition between us. I'm an accountability partner for one of my friends. ... And even for summer internships and stuff, we'll be competing for things like that." (Private)

"I think the inherent competition that arises, too, when you're working in a group, and somebody is like, 'Oh, this is so easy,' and you're struggling with it...I get a little inward fire that I need to find something that I found easy and he struggles with. So it kind of compels me to step up my game." (Research)

In summary, students reflected that the social learning advantage of working in a group as well as the competitiveness and motivation found in those groups were predominant benefits of participation in academic communities. That is, when participating in an academic group or team, these students felt that their understanding of curricular material and capability to perform improved. The power of teamwork was the driving motivator for most students to participate in academic co-curricular activities and groups. 


\section{Limitations and Implications}

Limitations: We recognize that in drawing data from only four institutions, the generalizability of our findings may be limited. However, the inclusion of four diverse types of institutions in the study does allow for the representation of a wide range of student experiences. Despite the relatively small size of the data set, we feel that our findings are valuable, as they provide insight not only into what students are doing outside of the classroom, but how students perceive these activities as linking to their overall academic experience.

Implications: This study has offered insight into which types of academic and learning communities are most important to students. In particular, informal study groups appear to be important for students across institution types, with lab groups and professional societies also playing important roles at certain schools. Because of institutional differences in academic community participation, it is important for practitioners to not only understand which communities students are most active in, but also which communities are making the most difference for students within a particular institution and program. Once these communities are identified, they can be supported better by faculty inside the classroom and out as well as by advisors and administrators.

\section{Concluding Remarks}

Engineering students appear to be most impacted by the power of the team in their participation in informal study groups, lab groups, and professional societies outside the classroom. The fact that most students, without prompting, reflected on the benefits of working in communities with respect to their academic lives outside of the classroom reaffirms that even introvert-dominated fields like engineering tend to seek and gain significant benefits from teamwork. However, these results must be interpreted with caution because it is the teams that evolve by student selfselection processes over time that most often provide these benefits, while success in assigned teams may not be as prevalent. Thus, educators may benefit from observing and examining the informal, self-assembled working teams students create in order to modify the way they organize, assign, diagnose, and support more formal project teams within courses and classroom.

\section{ACKNOWLEDGMENTS}

The authors would like to gratefully acknowledge the National Science Foundation for their support of this work under the REESE program (grant numbers DRL-0909817, 0910143, 0909659, 0909900, and 0909850). Any opinions, findings, and conclusions or recommendations expressed in this material are those of the author(s) and do not necessarily reflect the views of the National Science Foundation. The authors would also like to acknowledge valuable input from our external advisory board (Robin Adams, Purdue University, Shannon Gilmartin, Stanford University, and Karl Smith, University of Minnesota), helpful discussions with project member Don Peter at Seattle Pacific University, and data collection efforts from Ryan Campbell, Jeff Chen, Leah Freed, Xingyi Shi and Michael Weiller at the University of Washington; M. Gabriela Garcia, Jeremy Pincosy, Teresa McNamee and Rachel Sear from Minnesota State University, Mankato; Kathleen Maguire, Lynn Passanisi and Courtney Paull from Simmons College; Caitlin Hawkinson, Whitney Giaimo, Nicole Myr, Kara Pegram, and Yolanda Winberg from Seattle Pacific University; and Nicole Walker and Kala Bean from Tuskegee University. 


\section{Bibliography}

1. Allendoerfer, C., Wilson, D., Bates, R., Crawford, J., Jones, D., Floyd-Smith, T., ... \& Veilleux, N. (2012). Strategic pathways for success: The influence of outside community on academic engagement. Journal of Engineering Education, 101(3), 512-538.

2. Inman, P., \& Pascarella, E. (1998). The impact of college residence on the development of critical thinking skills in college freshmen. Journal of College Student Development, 39(6), 557-568.

3. Pascarella, E. T., \& Terenzini, P. T. (2005). How college affects students: A third decade of research. San Francisco, CA: Jossey-Bass.

4. Brint, S., \& Cantwell, A. M. (2010). Undergraduate time use and academic outcomes: Results from the University of California Undergraduate Experiences Survey. Teachers College Record, 112(9), 2441-2470

5. Kellogg, K. (1999). Learning Communities. Washington, DC: ERIC Clearinghouse on Higher Education,. (ED430512).

6. Barbatis, P. (2010). Underprepared, ethnically diverse community college students: Factors contributing to persistence. Journal of Developmental Education, 33(3), 14-24.

7. Astin, A. W. (1993). What matters in college? San Francicso, CA: Jossey-Bass.

8. Zhao, C., \& Kuh, G. (2004). Adding value: Learning communities and student engagement. Research in Higher Education, 45(2), 115-138.

9. Treisman, P. U. (1992). Studying students studying calculus: A look at the lives of minority mathematics students in college. College Mathematics Journal, 23(5), 362-372.

10. Hendry, G. D., Hyde, S. J., \& Davy, P. (2005). Independent student study groups. Medical Education, 39, 672-679.

11. Sokolove, P. G., \& Marbach-Ad, G. (1999). The benefits of out-of-class group study for improving student performance on exams: a comparison of outcomes in active-learning and traditional college biology classes. Journal on Excellence in College Teaching, 10(3), 49-67.

12. Douville, M. L. (2013). The effectiveness of mutual aid learning communities in online MSW practice courses. Journal of Teaching in Social Work, 33(1), 15-25.

13. Randolph, K. A., \& Krause, D. J. (2002). Mutual aid in the classroom: An instructional technology application. Journal of Social Work Education, 38(2), 259-271.

14. Floyd-Smith, T., Wilson, D., Campbell, R., Veilleux, N., Bates, R., Plett, M., Scott, E., \& Peter, D. (2010). A multi-institutional study of connection, community, and engagement in STEM education: Conceptual model development. In Proceedings of the ASEE (American Society for Engineering Education) Annual Conference \& Exposition, Louisville, KY.

15. Creswell, J. W., Plano-Clark, V. L., Gutmann, M. L., \& Hanson, W. E. (2003). Advanced mixed methods research designs. Handbook of mixed methods in social and behavioral research, 209-240, Thousand Oaks, CA: Sage Publications.

16. Creswell, J.W., \& Plano-Clark V.L. (2007). Designing and conducting mixed methods research. Thousand Oaks, CA: Sage Publications.

17. Creswell, J. W., Klassen, A. C., Plano Clark, V. L., \& Smith, K. C. (2011). Best practices for mixed methods research in the health sciences. Bethesda, MD: National Institutes of Health.

18. Johnson, R. B., \& Onwuegbuzie, A. J. (2004). Mixed methods research: A research paradigm whose time has come. Educational Researcher, 33(7), 14-26.

19. National Survey of Student Engagement (NSSE) (2012). NSSE 2012 Annual Results. Retrieved March 31, 2015, from http://nsse.iub.edu/NSSE 2012 Results/pdf/NSSE 2012 Annual Results.pdf.

20. Institute of International Education (2010). Study abroad by U.S. students slowed in 2008/09 with more students going to less traditional destinations. Retrieved on March 31, 2015, from http://www.iie.org/Who-We-Are/News-and-Events/Press-Center/Press-Releases/2010/2010-11-15-OpenDoors-US-Study-Abroad.

21. National Science Foundation (2009). Undergraduate enrollment in engineering programs by sex, enrollment status, racelethnicity, and citizenship. Retrieved March 31, 2015, from http://www.nsf.gov/statistics/wmpd/2013/pdf/tab2-10.pdf. 